1 Department of Occlusion, Fixed Prosthesis and Dental Materials, School of Dentistry, Federal University of Uberlândia, Uberlândia, $M G$, Brazil.

${ }^{2}$ Clinical Practice, Uberlândia, $M G$, Brazil.
Corresponding author:

Dr. Karla Zancopé

Department of Occlusion, Fixed

Prosthesis and Dental Materials,

School of Dentistry, Federal

University of Uberlândia, Uberlândia,

MG, Brazil. Av. Pará, 1720

Bloco 4LA sala 4LA-40,

Campus Umuarama,

$+55(34) 3225-8105$,

Zip Code: 38405-320, Uberlândia, Minas Gerais, Brazil.

Email karlazancope@gmail.com

Received: September 12, 2018

Accepted: April 27, 2019

\section{Influence of furnace type in the crystallization of lithium disilicate on bond strength and flexural strength}

Karla Zancope ${ }^{1, *}$, Thácio de Castro ${ }^{2}$, Lucas do Nascimento Tavares ${ }^{1}$, Marcel Santana Prudente ${ }^{2}$, Flávio Domingues das Neves ${ }^{1}$

Aim: The crystallization step is required for lithium disilicate ceramics to change color, improve the mechanical properties and yield material to support mouth loading. Several furnaces could complete the crystallization process. This study evaluated the flexural and bond strength of lithium disilicate ceramics crystallized by different furnaces with the presence or not of vacum and different holding time. Methods: Forty lithium disilicate samples were divided into two groups: Programat P300 - control group with vacuum and holding time 7 minutes (CG) and FVPlus- experimental group and without vacuum and holding time 25 minutes (EG) and submitted to 2 experimental tests: 3-point flexural strength test and micro shear bond strength test ( $\mu$ SBS). For this test, the surface of the samples was treated and $1 \mathrm{~mm}^{2}$ of resin cement was applied on the surface. The samples were stored in artificial saliva over 2 time periods ( 24 hours: TO; 1-month storage: T1). To analyze the morphologic crystals of the ceramics tested, one representative specimen from each group were analyzed by using Scanning Electron Microscopy (SEM). Results: There was no significant difference in 3-point flexural strength test between groups CG and EG $(p=0.984)$. The $\mu S B S$ results showed no statistical difference between groups, considering different storage time. There was no difference in the 3-point flexural strength and $\mu S B S$ for lithium disilicate samples regardless of heat treatment of furnace type. The storage time had no influence on the $\mu$ SBS. No differences were noted in the shape and size of these crystals when comparing the furnace analyzed by SEM images. Conclusion: Different furnaces did not influence the flexural and bond strength of lithium disilicate ceramics.

Keywords: Ceramics. Shear Strength. Lithium Compounds. 


\section{Introduction}

The development of mechanical properties, aesthetic, biocompatibility of glass ceramics have improved and enabled the manufacturing of all-ceramic crowns ${ }^{1}$. There are several ceramic materials in the market with different aesthetic and mechanical properties: feldspathic, leucite, lithium disilicate, silicate, non-vitreous, alumina and zirconia2-4. Lithium disilicate (IPS e.max, Ivoclar Vivadent, Schaan, Liechtenstein) is a glass-reinforced ceramic $\mathrm{Li}_{2} \mathrm{O}-2 \mathrm{SiO}_{2}$ with different clinical applications: inlays, onlays, anterior and posterior site crowns, irrespectively. Fixed prostheses up to three elements from anterior to the second premolar are also possible given its high resistance ${ }^{5-6}$. Survival rates in the posterior region were $96.3 \%$ in at 4 years ${ }^{7}, 97.8 \%$ at 5 years and $96.7 \%$ at 10 years ${ }^{8}$. Among the high strength ceramics, lithium disilicate has an aesthetic advantage due to its higher translucency ${ }^{4-9}$ and reduced chipping ${ }^{10}$.

Lithium disilicate commercial presentations are machinable blocks and press ingots with different color, translucency and opacity ${ }^{11}$. Machinable blocks (IPS e.max CAD, Ivoclar Vivadent, Schaan, Liechtenstein) are presented in pre-crystallized form with bluish color. This pre-crystallized form allows the block to be machined without excessive wear of the diamond drill or damage to the material. The crystal size ranges from 0.2 to $1.0 \mu \mathrm{m}$ in the crystalline phase with approximately $40 \%$ of the volume of lithium metasilicate crystals, presenting reduced mechanical properties ${ }^{12}$. After the restoration milling, the highest temperature of the crystallization process induced the growth of lithium disilicate crystals, reducing all lithium metasilicates and improving the physical and mechanical properties of ceramic ${ }^{13-16}$. The crystal grain sized $1.5 \mu \mathrm{m}$, and a crystalline phase expanded performing 70\% embedded in the glass matrix ${ }^{4,12}$.

This process is established with a suitable furnace manufactured by Ivoclar Vivadent (Schaan, Liechtenstein). The crystallization process based on restoration heat treatment with similar steps of entry time, entry temperature, heating rate, final temperature. The literature showed that the growth of $\mathrm{Li}_{2} \mathrm{O}-2 \mathrm{SiO}_{2}$ crystals within the IPS e.max CAD blocks was irrespective of overall heating time but dependent on a minimum temperature threshold $\left(780^{\circ} \mathrm{C}\right)^{17}$. However the presence or not of vacuum and different holding time in different furnace type/heat treatment should be verified.

These variables could affect the mechanical properties and ceramic microstructures/ bonding achieved at the end of crystallization. Therefore, the aim of this study was evaluated the flexural strength, bond strength and crystal grain size of lithium disilicate blocks crystallized with different furnaces type. The null hypothesis was that the crystallization process, with or without vacuum does not interfere with the flexural and bond strength of the lithium disilicate ceramics.

\section{Materials and methods}

Forty pre-crystallized lithium disilicate (IPS e.max CAD, Ivoclar Vivadent, Schaan, Liechtenstein) samples were obtained and divided into 2 groups according to the crystallization process with two different furnace types: Programat P300 furnace (Ivoclar Vivadent, Schaan, Liechtenstein) - control group (CG) and FVPlus furnace (EDG, São Carlos, $\mathrm{SP}$, Brazil) - experimental group (EG), following manufacturers' recommendations. The 
heating schedule is shown in Table 1. The samples (CG and EG) were carefully distributed and positioned in a refractory basis and the crystallization process was done.

\section{Specimen preparation to the for microshear bond strength test}

After the crystallization, ten CG blocks and ten EG blocks were included in PVC cylinders with polystyrene resin (Aerojet, Santo Amaro, SP, Brazil). Next, ceramic surfaces were ground with wet carbide silicon sandpaper (\#600, 800, 1200, Norton, Campinas, SP, Brazil) for 20 seconds (s) for shape standardization. The ceramic blocks surfaces were treated with hydrofluoric acid at 10\% (Condac porcelain, FGM, Joinville, PR, Brazil) for 20 s, followed by filtered water spray washing for 1 minute and subsequently dried with oil free air. The pre-hydrolyzed silane was applied (RelyX ceramic primer, 3M ESPE, St. Paul, USA) on the ceramic surface for 60 seconds ${ }^{18-21}$.

The silicone matrix was positioned in the ceramic surface to prepare the cement specimens for the $\mu$ SBS. The silicone matrix had 6 holes with $1.0 \mathrm{~mm}$ of diameter and $3 \mathrm{~mm}$ spacing between them ${ }^{22-24}$. The holes were filled with dual self-adhesive resin cement (RelyX U200, 3M ESPE, St. Paul, USA). The polyester strip was positioned on the already filled holes followed by the gentle pressure of a metal object for 2 min. The specimens were polymerized for 40 seconds with LED (Radii Cal, SDI, Bayswater, Australia). After complete polymerization, the silicone mold was removed carefully removed and a six 1 $\mathrm{mm}^{2}$ resin cement bonded to the surface of the ceramic. were obtained. Two resin cement specimens were selected for immediate test (24 hours) (TO) and two were tested after 1 month storage in artificial saliva at $37^{\circ} \mathrm{C}$ and relative humidity $(\mathrm{T} 1)$. The artificial saliva simulating the oral environment provides clinically relevant failure modes ${ }^{25,26}$.

The microshear bond strength ( $\mu$ SBS) test was conducted by means of microtensile mechanical tests (OM100, Odeme Dental Research, Pinhais, PR, Brazil). An orthodontic wire 0.2 millimeters in diameter (Morelli, Sorocaba, SP, Brazil) was selected for traction and positioned in the resin cement specimen cylinders aligned with the applying force direction ${ }^{27}$. The equipment was adjusted under horizontal loading speed of $0.7 \mathrm{~mm} / \mathrm{min}^{26}$. After performing the mechanical tests, the samples were classified considering the failure type (adhesive failure, cohesive failure or mixed failure) with an optical microscope (Mitutoyo, Illinois, USA). The flaws were classified as cohesive (failure within the cement or ceramic), adhesive (at the interface between cement and ceramics) and mixed (including ceramic / cement cohesive and adhesive failure). Cohesive failure in ceramic is more unusual in this type of the tes ${ }^{28,29}$.

\section{Specimen preparation to for flexural strength}

3-point test was the one chosen for flexural strength ${ }^{30}$. Among the flexural tests available was chosen the 3 -point test ${ }^{30}$. Ten pre-crystallized samples from each group was

Table 1. Crystallization parameters for post-milling heat treatment.

\begin{tabular}{lccccccc}
\hline & Entry time & $\begin{array}{c}\text { Entry } \\
\text { temp. }\end{array}$ & $\begin{array}{c}\text { Heating } \\
\text { rate }\end{array}$ & $\begin{array}{c}\text { Final } \\
\text { temp. }\end{array}$ & $\begin{array}{c}\text { Holding } \\
\text { time }\end{array}$ & $\begin{array}{c}\text { Start } \\
\text { vacuum }\end{array}$ & $\begin{array}{c}\text { Release } \\
\text { vacuum }\end{array}$ \\
\hline Programat P300 & $6: 00 \mathrm{~min}$ & $403^{\circ} \mathrm{C}$ & $90^{\circ}$ & $820^{\circ}$ & $7: 00 \mathrm{~min}$ & $550^{\circ} \mathrm{C}$ & $820^{\circ} \mathrm{C}$ \\
\hline FVPlus & $6: 00 \mathrm{~min}$ & $400^{\circ} \mathrm{C}$ & $90^{\circ}$ & $820^{\circ}$ & $25: 00 \mathrm{~min}$ & - & - \\
\hline
\end{tabular}


sectioned by using the ISOMET 1000R machine (Buehler, Lake Bluff, IL, USA). A digital pachymeter (Digimatic Caliper, Mitutoyo Absolute, Mitutoyo, Illinois, USA) was used to check the dimensions of the sticks: about $20 \mathrm{~mm}$ long, $4 \mathrm{~mm}$ wide and $1.2 \mathrm{~mm}$ thick. After the standardization of dimensions, the sticks were carefully positioned in the firing basis and crystallized according to the description on Table 1.

Each crystallized lithium disilicate stick was put on the mechanical testing machine (EMIC 2000 DL, São José dos Pinhais, PR, Brazil). The stick was placed on two cylinders of approximately $2 \mathrm{~mm}$ diameter and $16 \mathrm{~mm}$ apart from each other. The flexural strength test consisted of a compressive load of $50 \mathrm{kgf}$ applied on the sample through a $2 \mathrm{~mm}$ diameter piston positioned at half the distance between the supports at a speed of $0.5 \mathrm{~mm} /$ minute all the way to sample breakage. Flexural strength values were expressed in $\mathrm{MPa}^{31}$.

\section{Scanning Electron Microscopy (SEM) Analysis}

To analyze the morphologic crystals of the ceramics tested, one representative specimen from each group were analyzed by using Scanning Electron Microscopy (SEM - VEGA 3, TESCAN, LMU, Kohoutovice, Czech Republic) analysis to depict the etched surface morphology. Within this group were etched with $10 \%$ hydrofluoric acid (HF) (Condac Porcelana, FGM, Joinville, SC, Brazil) for $20 \mathrm{~s}$ and washed. After that, using $70 \%$ alcohol and distilled water, an ultrasonic bath with distilled water for 10 min followed in order to remove HF etching residue. Afterwards, specimens were mounted on coded brass stubs and sputter-coated with gold-palladium for $60 \mathrm{~s}$ at $45 \mathrm{~mA}$ (QR 150ES, Quorum Technologies, Laughton, Lewes, UK) to obtain images with better quality allowing visualization of the crystals to obtain images with better quality allowing visualization of the crystals. The images were obtained using $5.0 \mathrm{kV}$ accelerated voltage and 10.000 original magnification. Ten photomicrographs were taken per etched specimen to assess the crystal size using Image J processing program.

\section{Statistical Analysis}

Data were tabulated and analyzed using SigmaPlot 12.0 software. The flexural strength, microshear bond strength and microstructural analysis test data underwent Student t-test $(\mathrm{a}=0.05)$ for comparison between and intra groups.

\section{Results}

One resin cement specimen from EG (T1) group failed during positioning of orthodontic wire and another one was selected for testing. Maximum and minimum values, the average of values, standard deviation and $p$-value according to storage time are shown in Table 2. There was no significant difference regarding inter and intra groups tested. The percentages of failure type after micro shear test are listed in figure 1. There was no cement and ceramic cohesive failure. More adhesive failures at the bonding interface and less mixed failure were detected.

Data descriptive statistics from the three-point flexural strength test are described in figure 2 . There was no statistically significant difference $(P=0.984)$ between the flexural strength values obtained for CG and EG. 
Table 2. $\mu$ SBS of crystallization process $x$ storage time and confidence interval (MPa).

\begin{tabular}{lccccc}
\hline \multirow{2}{*}{ Groups } & \multicolumn{4}{c}{ Storage time } & P-value \\
\cline { 2 - 5 } & Imediate (T0) & $\begin{array}{c}\text { Confiance } \\
\text { interval (T0) }\end{array}$ & 30 days (T1) & $\begin{array}{c}\text { Confiance } \\
\text { interval (T1) }\end{array}$ & \\
\hline CG & $17.89 \pm 5.92$ & $11.96-23.81$ & $17.11 \pm 6.37$ & $10.73-23.48$ & 0.780 \\
\hline EG & $15.04 \pm 4.53$ & $10.50-19.57$ & $14.94 \pm 5.28$ & $9.65-20.22$ & 0.964 \\
\hline P-value & 0.243 & \multicolumn{5}{c}{0.415} \\
\hline
\end{tabular}

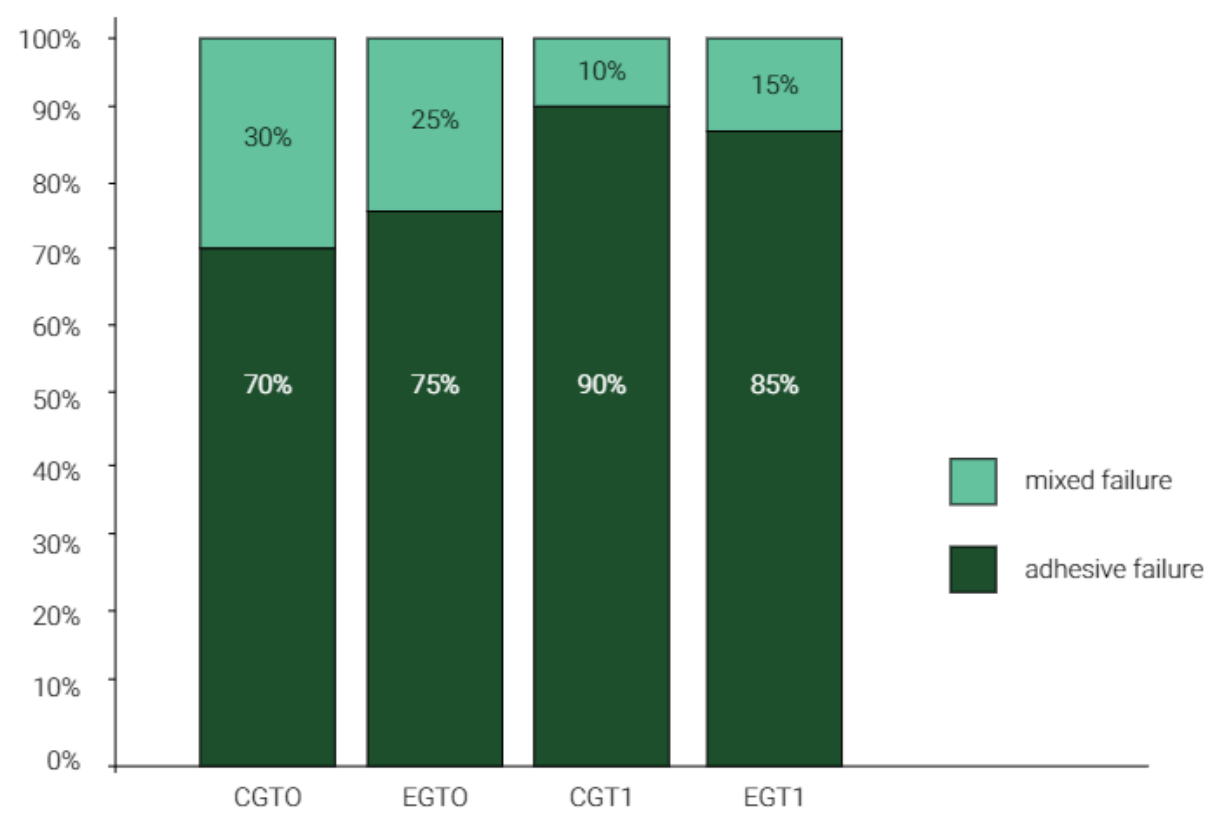

Figure 1. Quantitative and qualitative results of the failure pattern after microshear bond strength.

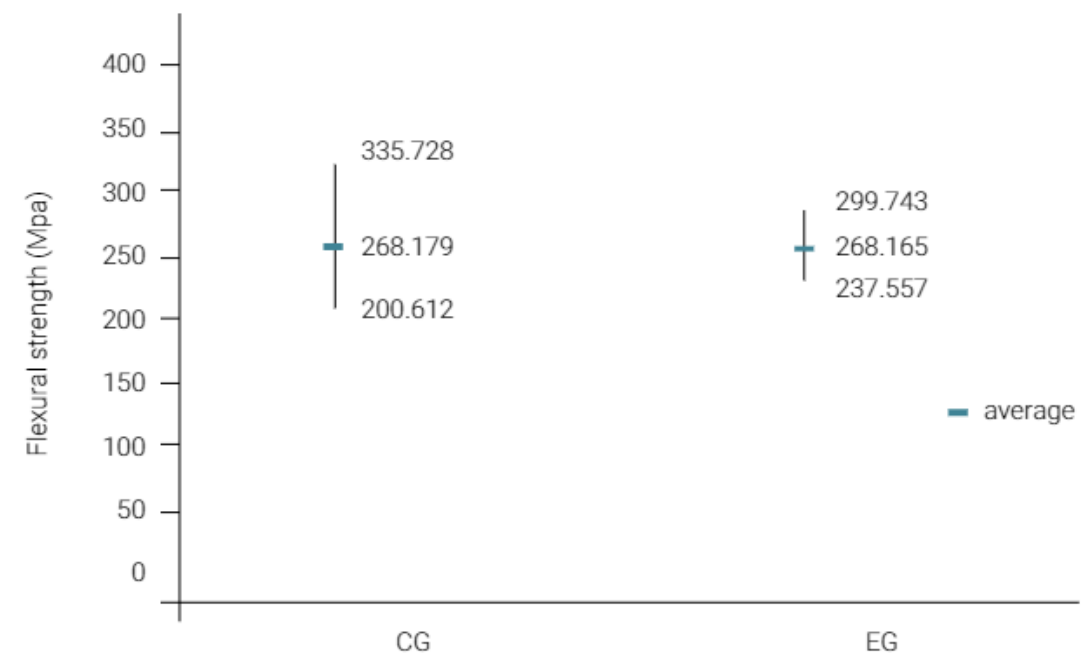

Figure 2. Means and standard deviations of the flexural strength values (MPa) of the samples CG and EG. 
After the crystallization process, the CG and EG were evaluate with SEM images in Figures 3 and 4, respectively. It was possible to analyze using etched $10 \%$ hydrofluoric acid, the IPS e.max CAD ceramics showed elongated spindle shaped lithium disilicate crystals. The Lithium disilicate crystals of group GC have a mean length of $0.5 \mu \mathrm{m}$ and for the group EG $0.4 \mu \mathrm{m}$ in their pre-crystallized phase. After crystallization, the mean crystal size increases up to $3.0 \mu \mathrm{m}$ of group GC and for the group EG $2.9 \mu \mathrm{m}$. However, no differences were noted in the shape and size of these crystals when comparing the furnace analyzed $(P=0.824)$.

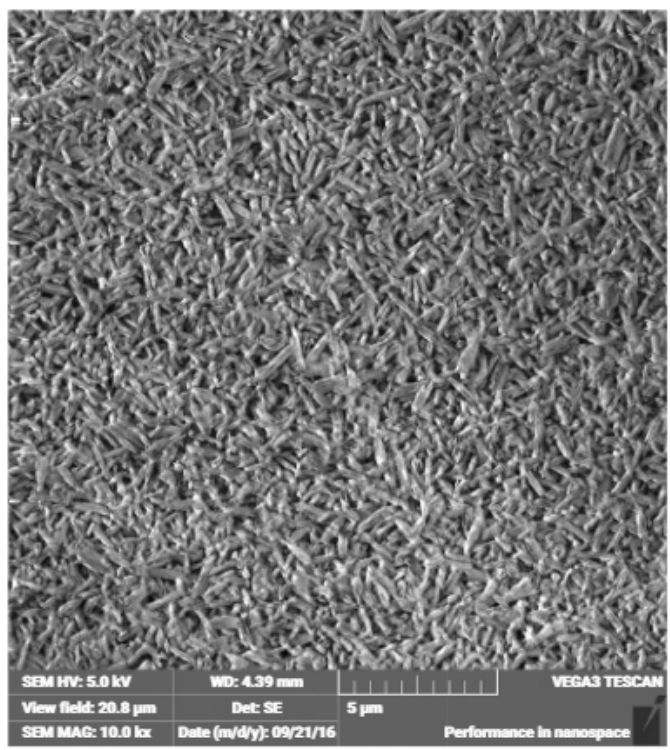

Figure 3. SEM images of CG group after the crystallization process, using the Programat P300 furnace, Ivoclar.

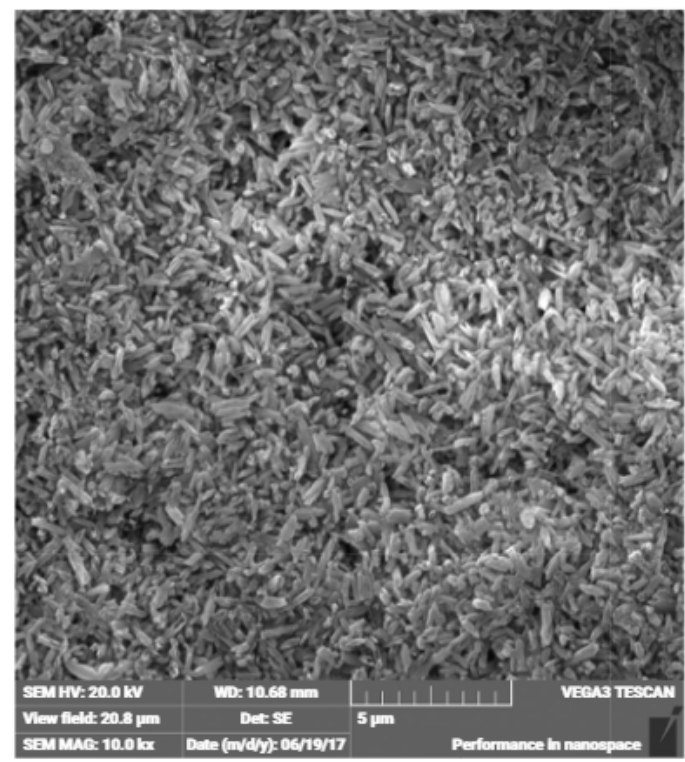

Figure 4. SEM images of EG group after the crystallization process, using the FVPlus furnace, EDG. 


\section{Discussion}

The null hypothesis was that the crystallization process/heat treatment, with or without vacuum and different holding time does not interfere with the flexural, bond strength and crystal size of the lithium disilicate ceramics was accepted.

The similar results in the tested groups lead us to believe that by using either of the two furnaces, the crystallization process induced the growth of lithium disilicate crystals, reducing all lithium metasilicates and improving the physical and mechanical properties of ceramic ${ }^{13-15}$. The results of flexural strength values are in accordance with literature ${ }^{32}$. No differences were detected in heat treatment without vacuum, and protracted holding time $\left(820^{\circ} \mathrm{C} \mathrm{H} 25 \mathrm{~min}\right)$ provided same flexural. Then the growth of $\mathrm{Li}_{2} \mathrm{O}-2 \mathrm{SiO}_{2}$ crystals within the IPS e.max CAD blocks was irrespective of overall heating time but dependent on a minimum temperature threshold $\left(780^{\circ} \mathrm{C}\right)^{17}$. Specimens heated above the minimum temperature threshold $\left(780^{\circ} \mathrm{C}\right)$ exhibited enhanced flexural strength over groups not heated above $780^{\circ} \mathrm{C}^{32}$.

According to mSBS results, storage in artificial saliva was chosen because since it simulated the best conditions of oral environments ${ }^{25,26}$. Other studies selected distilled water storage; however, it could compromise the accuracy of the results ${ }^{25,26}$. The $\mu$ SBS post-storage results regarding storage time were statistically similar. On the other hand, 30-day artificial saliva storage was considered too short to promote significant hydrolytic degradation of the cement.

One of the resin cement specimen from EG (T1) group failed during positioning of orthodontic wire and other resin cement specimens were selected. Specimens under $1.1 \mathrm{~mm}^{2}$ adhesive interface can fail even before mechanical testing ${ }^{33}$. There were more adhesive and mixed failures at the bonding interface ${ }^{27}$. Cohesive failure in ceramic is more unusual in this type of the test 28,29 .

The SEM images enabled the evaluate topography of the dental ceramics tested in this study. The lithium disilicate partially crystallized stage, showed typical lithium metasilicate crystals embedded in a glass matrix with typical acicular shaped grains. After the heat treatment (crystallized stage), the crystalline microstructure changed into a denser form, being similar for both dental ceramics tested and became more dense and homogeneous restorations to receiving masticatory forces ${ }^{30}$. Lithium disilicate crystals have an average length of $0.5 \mu \mathrm{m}$ in their pre-crystallized phase and after crystallization, the average crystal size increases up to $3.0 \mu \mathrm{m}$, as observed in the present study ${ }^{17}$.

The authors could conclude that the presence or absence of vacuum and different holding time of furnace type/heat treatment demonstrated no difference on flexural strength of lithium disilicate IPS e.max CAD or on the bond strength of IPS e.max CAD with resin-cement or on crystal grain size. Lastly, storage time (30 days) in artificial saliva demonstrated no difference on shear strength between e.max CAD and resin-cement.

\section{Acknowledgments}

The authors want to thank Odontomega, CAPES, CNPq, FAPEMIG, CPBio and NEPRO Research Group for its contribution for this work. 


\section{References}

1. Pjetursson BE, Sailer I, Zwahlen M, Hämmerle $\mathrm{CH}$. A systematic review of the survival and complication rates of all-ceramic and metal-ceramic reconstructions after an observation period of at least 3 years. Part I: Single crowns. Clin Oral Implants Res. 2007;18 Suppl 3:73-85. Review. Erratum in: Clin Oral Implants Res. 2008;19(3):326-8.

2. Pagani C, Miranda CB, Bottino MC. Relative fracture toughness of different dental ceramics. J Appl Oral Sci. 2003;11(1):69-75.

3. Della Bona A, Kelly JR. The clinical success of all-ceramic restorations. J Am Dent Assoc. 2008;139 Suppl:8S-13S.

4. Fasbinder DJ, Dennison JB, Heys D, Neiva G. A clinical evaluation of chairside lithium disilicate CAD/CAM crowns: a two-year report. J Am Dent Assoc. 2010;141 Suppl 2:10S-4S,

5. Sorensen JA, Cruz M, Mito WT, Raffeiner O, Meredith HR, Foser HP. A clinical investigation on three-unit fixed partial dentures fabricated with a lithium disilicate glass-ceramic. Pract Periodontics Aesthet Dent. 1999;11(1):95-106; quiz 108

6. Kheradmandan S, Koutayas SO, Bernhard M, Strub JR. Fracture strength of four different types of anterior 3-unit bridges after thermo-mechanical fatigue in the dual-axis chewing simulator. J Oral Rehabil. 2001;28(4):361-9

7. Reich S, Schierz O. Chair-side generated posterior lithium disilicate crowns after 4 years. Clin Oral Investig. 2013;17(7):1765-72. doi: 10.1007/s00784-012-0868-0.

8. Pieger S, Salman A, Bidra AS. Clinical outcomes of lithium disilicate single crowns and partial fixed dental prostheses: a systematic review. J Prosthet Dent. 2014;112(1):22-30. doi: 10.1016/j.prosdent.2014.01.005.

9. Gracis S, Thompson VP, Ferencz JL, Silva NR, Bonfante EA. A new classification system for all-ceramic and ceramic-like restorative materials. Int J Prosthodont. 2015;28(3):227-35. doi: 10.11607/ijp.4244.

10. Lin WS, Ercoli C, Feng C, Morton D. The effect of core material, veneering porcelain, and fabrication technique on the biaxial flexural strength and Weibull analysis of selected dental ceramics. J Prosthodont. 2012;21(5):353-62. doi: 10.1111/j.1532-849X.2012.00845.x.

11. Neves FD, Prado CJ, Prudente MS, Carneiro TA, Zancopé K, Davi LR, et al. Micro-computed tomography evaluation of marginal fit of lithium disilicate crowns fabricated by using chairside CAD/CAM systems or the heat-pressing technique. J Prosthet Dent. 2014;112(5):1134-40. doi: 10.1016/j.prosdent.2014.04.028.

12. Ritter RG. Multifunctional uses of a novel ceramic-lithium disilicate. J Esthet Restor Dent. 2010;22(5):332-41. doi: 10.1111/j.1708-8240.2010.00362.x.

13. McLaren EA, Figueira J. Updating Classifications of Ceramic Dental Materials: A Guide to Material Selection. Compend Contin Educ Dent. 2015;36(6):400-5; quiz 406, 416.

14. Borom MP, Turkalo AM, Doremus RH. Strength and microstructure in lithium disilicate glass-ceramics. J Amer Ceram Soc. 1975;58(9-10):385-91. https://doi.org/10.1111/j.1151-2916.1975.tb19004.x.

15. Höland W, Apel E, van 't Hoen C, Rheinberger V. Studies of crystal phase formations in high-strength lithium disilicate glass-ceramics. J Non-Cry Sol. 2006;352(15):38-9. https://doi.org/10.1016/j.jnoncrysol.2006.06.039.

16. Rekow ED, Silva NR, Coelho PG, Zhang Y, Guess P, Thompson VP. Performance of dental ceramics: challenges for improvements. J Dent Res. 2011;90(8):937-52. doi: 10.1177/0022034510391795.

17. Lien W, Roberts HW, Platt JA, Vandewalle KS, Hill TJ, Chu TM. Microstructural evolution and physical behavior of a lithium disilicate glass-ceramic. Dent Mater. 2015;31(8):928-40. doi: 10.1016/j.dental.2015.05.003. 
18. Lise DP, Perdigão J, Van Ende A, Zidan O, Lopes GC. Microshear Bond Strength of Resin Cements to Lithium Disilicate Substrates as a Function of Surface Preparation. Oper Dent. 2015;40(5):524-32. doi: 10.2341/14-240-L.

19. Tian T, Tsoi JK, Matinlinna JP, Burrow MF. Aspects of bonding between resin luting cements and glass ceramic materials. Dent Mater. 2014,30(7):e147-62. doi: 10.1016/j.dental.2014.01.017.

20. Neis CA, Albuquerque NL, Albuquerque Ide S, Gomes EA, Souza-Filho CB, Feitosa VP, et al. Surface treatments for repair of feldspathic, leucite - and lithium disilicate-reinforced glass ceramics using composite resin. Braz Dent J. 2015;26(2):152-5. doi: 10.1590/0103-6440201302447.

21. Zogheib LV, Bona AD, Kimpara ET, McCabe JF. Effect of hydrofluoric acid etching duration on the roughness and flexural strength of a lithium disilicate-based glass ceramic. Braz Dent J. 2011;22(1):45-50.

22. Della Bona A, Anusavice KJ, Mecholsky JJ Jr. Failure analysis of resin composite bonded to ceramic. Dent Mater. 2003;19(8):693-9.

23. Della Bona A, Anusavice KJ, Shen C. Microtensile strength of composite bonded to hot-pressed ceramics. J Adhes Dent. 2000;2(4):305-13.

24. Raposo LH, Armstrong SR, Maia RR, Qian F, Geraldeli S, Soares CJ. Effect of specimen gripping device, geometry and fixation method on microtensile bond strength, failure mode and stress distribution: laboratory and finite element analyses. Dent Mater. 2012;28(5):e50-62. doi: 10.1016/j.dental.2012.02.010.

25. Wegner SM, Gerdes W, Kern M. Effect of different artificial aging conditions on ceramic-composite bond strength. Int J Prosthodont. 2002;15(3):267-72.

26. Nawafleh N, Hatamleh M, Elshiyab S, Mack F. Lithium Disilicate Restorations Fatigue Testing Parameters: A Systematic Review. J Prosthodont. 2016;25(2):116-26. doi: 10.1111/jopr.12376.

27. Armstrong S, Geraldeli S, Maia R, Raposo LH, Soares CJ, Yamagawa J. Adhesion to tooth structure: a critical review of "micro" bond strength test methods. Dent Mater. 2010;26(2):e50-62. doi: 10.1016/j.dental.2009.11.155.

28. Moharamzadeh K, Hooshmand T, Keshvad A, Van Noort R. Fracture toughness of a ceramic-resin interface. Dent Mater. 2008;24(2):172-7.

29. Hooshmand T, Rostami G, Behroozibakhsh M, Fatemi M, Keshvad A, van Noort R. Interfacial fracture toughness of different resin cements bonded to a lithium disilicate glass ceramic. J Dent. 2012;40(2):139-45. doi: 10.1016/j.jdent.2011.12.005.

30. Jin J, Takahashi $\mathrm{H}$, Iwasaki N. Effect of test method on flexural strength of recent dental ceramics. Dent Mater J. 2004;23(4):490-6.

31. Yen TW, Blackman RB, Baez RJ. Effect of acid etching on the flexural strength of a feldspathic porcelain and a castable glass ceramic. J Prosthet Dent. 1993;70(3):224-33.

32. Albero A, Pascual A, Camps I, Grau-Benitez M. Comparative characterization of a novel cad-cam polymer-infiltrated-ceramic-network. J Clin Exp Dent. 2015;7(4):e495-500. doi: 10.4317/jced.52521.

33. Phrukkanon S, Burrow MF, Tyas MJ. Effect of cross-sectional surface area on bond strengths between resin and dentin. Dent Mater. 1998;14(2):120-8. 